(昭和 36 年 10 月 16 日受理)

\title{
直接染色における繊維素表面層の飽和吸着量について
}

\author{
群馬大学工業短期大学部 島田雅

\section{THE SATURATION VALUE OF ADSORPTION OF THE SURFACE LAYER OF CELLULOSE IN DIRECT DYEING}

夫

By Masao Shimada

(Faculty of Engineering, Gunma Universify, Kiryu City, Gunma Prefecture, Japan)

\begin{abstract}
Adsorption isotherms of Congo Red, Benzopurpurine $4 \mathrm{~B}$ and Benzopurpurine $10 \mathrm{~B}$, from the dyebath within the range of concentrations $1.5 \times 10^{-s}$ mole dyes per litre have been determined on cellophane sheets.

The results of these experiment are as following :

The ratio between the ionic products of dye anion and $\mathrm{Na}$ ion concentrations from dyebath and from cellophane sheet cease to maintain the constant value, in case where the cellophane sheet adsarbs more than about $4 \times 10^{-2}$ mole per $\mathrm{kg}$. This result is due to the fact that the adsorption amount is closely connected with the saturation value ; for that reason, this tendency becomes more conspicuous as the adsorption amount goes on increasingly.

(Received October 16, 1961)
\end{abstract}

\section{1. 腥言}

说来の直接染料の䋐維素に対する標潐親和力の求め方 れはまだ多くの問題がある。本論文では，そのうちの一 つである絨維素相吸着界面に执ける飽和吸着量の問題に ついて険討を陚みた。

緎維素綞維の染色儿招いて，直接染料が飽和吸着量を 有するであるうことは，すでに Handson \& Neale'), Vickerstaff ${ }^{2}$ らに上つて示崚されている。しかしなが

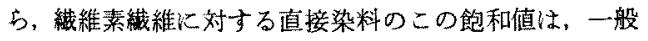
イタンパ質䋊維以対して酸性染料が示すよ5な明確な すのでなく，染料の種類や染浴の条件などによて変 動し，高濃度染色での染着動は明らかてない。

本実験では，䋊維素に対する親和力の大きい染料で は，吸着面の餡和が容易になされるである5と考文て， 此較的吸着量の多いとされている3種の道接染料を選 び，一連の染浴染料漊度で染着量弆测定した。その結 果，染着濃度の大なるところでは，希薄な部分にくらべ てかなり異なつた染着挙動を示すことを知つたので，飽 和吸着との関連について検討した。

\section{2. 実 験 方 法}

被染物山，東京七ロハン紙株式会社製 No. 300のセF ハン䋑で，厚さ約 $0.0023 \mathrm{~mm}$ のbのを使用した。染料 は, Congo Red (以下 $\mathrm{CR}$ と略記), Benzopurpurine $4 \mathrm{~B}(4 \mathrm{~B})$, 同じく $10 \mathrm{~B}(10 \mathrm{~B})$ の 3 種て, いずれも市販 品を Robinson \& Mills の方法で精製，さらにエタノー
ルと水 (エタノール 1 : 水 $0.5 \sim 1)$ より再結晶した。染 浴染料濃度は，打もに $10^{-6} \sim 10^{-4} \mathrm{~mol} / l$ とした。染色温 度は，90，70，50 $0^{\circ}$ の 3 点とし， $2 \mathrm{~g} / \mathrm{l}$ の食塩を加之た 染浴と，染料だけで食塩を加えない染浴による染色の2 采列とした。しかし食程無添加の系列では前者にくらぺ て再現性がやや悪くなり，ことに低温度では著しいのた $50^{\circ} \mathrm{C}$ での染色を除外した。

染色は封管中で括こない，染色时間は，むらかじ平

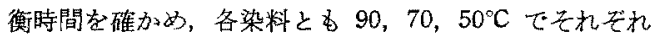
6, 24, $72 \mathrm{hr}$ とした。染着量は，染色也中ハンを 5７

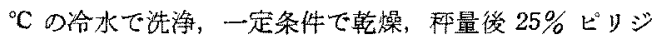
ン水溶液で抽出して比色定量した。染浴染料濖度は，染 浴初濃度から七ロ ツンに染着した量を差引き平衡特の濃 度とした。一回の染色に用いた七口ハンは約 $150 \mathrm{mg}$, 染

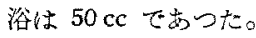

また染料濃度を異にする染浴中ての染料分子の集合状 熊の变化を考察するために，染浴の吸収スベタトルを測 定した。測定时の温度は分光光電光度計のセ儿室内につ けたニクロム線で保温し，電王を調節して $70 \pm 1^{\circ} \mathrm{C} と し$ た。測定時の溶液の蒸発は, 七ルの上面を流動パフォィ ンでおおい，これる眆いだ。なお分光光電光度計は日立 EPB-U 型を用いた。

\section{3. 寒 験 結 果}

\section{a）一定量の食塩を含む染浴からの染色}

食塩濃度, $2 \mathrm{~g} / l$ に打ける染浴染料濃度と染着量との

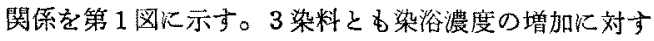




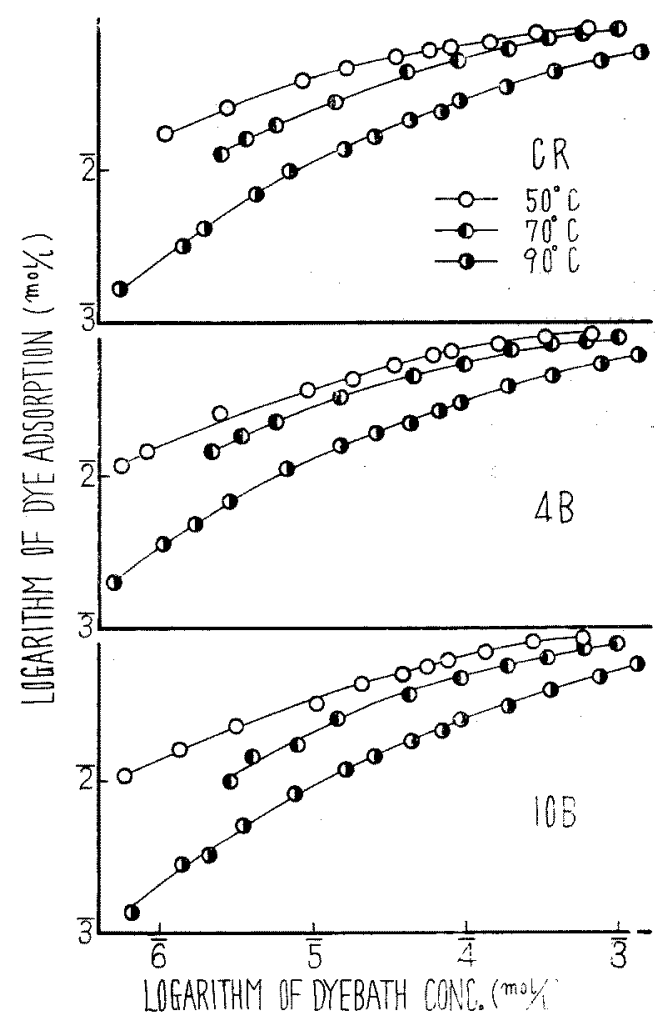

Fig. 1. Adsorption isotherms of dyes on the cellophane sheet from the solution containing $2 \mathrm{~g} / / \mathrm{NaCl}$.

る染着量の增加の割合は，染着量が大きくなるにしたが つて徐々に減少し，一定值に近つく傾向を示している。

b）食塩を含まない染浴からの染色

次に，a）と淰ほ同一染色条件での食塩無添加の染色 結果を第 2 図に示す。染着量は、）よりもはるかに少な い。机高濃度部分ての染着量の增加率が極端に娍少す るようなことはない。

c) 吸収スベクトル

$70^{\circ} \mathrm{C}$ 江打方, 染料水溶液の吸收スペクトルを常法 により澌定した。溶液は調整後 $4 \sim 6 \mathrm{hr}, 70^{\circ} \mathrm{C}$ K保たせ たるのを使用した。。染料濃度は $0.2 \sim 20 \times 10^{-5} \mathrm{~mol} / l$ と し，2g/l の食塩定添加した系列と，添加しない采列と について，極大吸収の分子吸光䒺数它求めた。(Fig. 4 参照）両系列之无，染料濃度の相違による分子吸光荣数 の変化はみられない。

\section{4. 考察}

直接染料の染着機構に, Donnan の膜平衡の成立; そ の他促来の仮定を入れた等温吸着式として, Vickerstaff

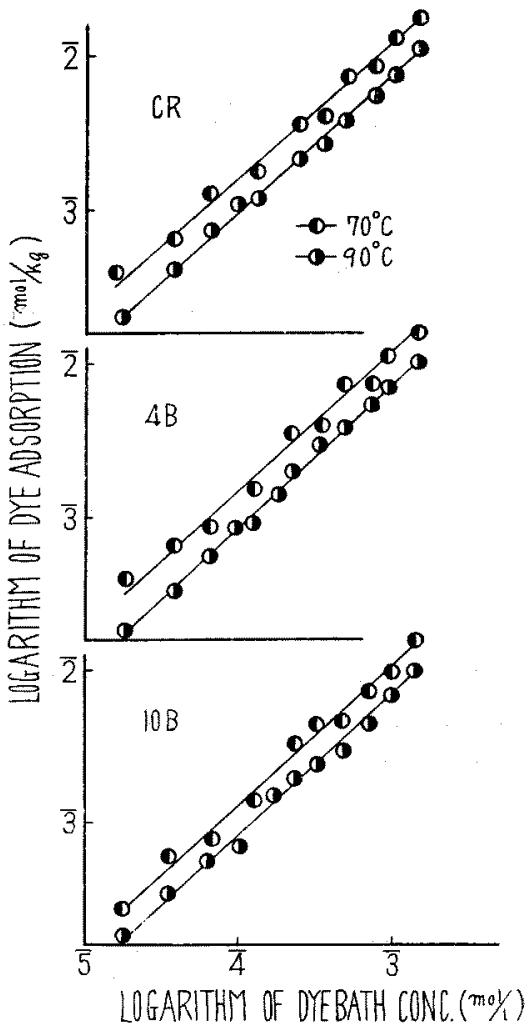

Fig. 2. Adsorption isotherms of dyes on the cellophane sheet from the solution without $\mathrm{NaCl}$.

により次式が導がれてる゙。

$$
\log [\mathrm{D}]_{\phi}[\mathrm{Na}]_{\phi^{z}}-\log [\mathrm{D}]_{\sigma}[\mathrm{Na}]_{\sigma^{z}}=C_{1}
$$
ただし

$$
[\mathrm{Na}]_{\phi}=[\mathrm{D}]_{\phi}\left\{z / 2+\left(z^{2} / 4+[\mathrm{Na}]_{\sigma}[\mathrm{Cl}]_{\sigma} \mathrm{V}^{2} /[\mathrm{D}]_{\phi^{2}}\right)^{1 / 2}\right\}
$$

ここで $[\mathrm{D}]_{\phi},[\mathrm{Na}]_{\phi}$ 括よび $[\mathrm{D}]_{\sigma},[\mathrm{Na}]_{\sigma}$ はそれそれ䋐 維素相および染浴相の染料イオンとナトリウムイオンの 濃度をあらわし，V は絏維素表面周容積を示す。 $\mathrm{C}_{1} \mathrm{~K}$ ついては $-\Delta \mu^{0} / 2.3 \mathrm{RT}+\log \left([\mathrm{S}]_{a}-[\mathrm{D}]_{a}\right)+\log \mathrm{V}^{(z+1)}$ を意味する。 $\Delta \mu^{0}$ は親和力，[D] $a$ は界面の吸着量， [S]aはその飽和值である。しかし，慣例として，一般 に得られているこの種の染色結果では，[D $]_{a}$ は $[S]_{a} よ$ りはるがであるとして， $\log [\mathrm{S}]_{a}$ を第2 項の近似と し，これを一定値と考觉て第 1 項に含ませ， $A \mu^{0}$ を求め ている。

染浴が $2 \mathrm{~g} / l$ の食塩を含む場合の染色結果 (Fig.1) を 上式の䄉維・染浴両相に適用Lて $\log [\mathrm{D}]_{\phi}[\mathrm{Na}] \phi^{2}$ と $\log [\mathrm{D}]_{\sigma}[\mathrm{Na}]_{\sigma^{2}}$ の関係を求めると第 3 図の上5伈なる。 ただし [Na $]_{\phi}$ 算出に必要な V の值としては，濃度の 


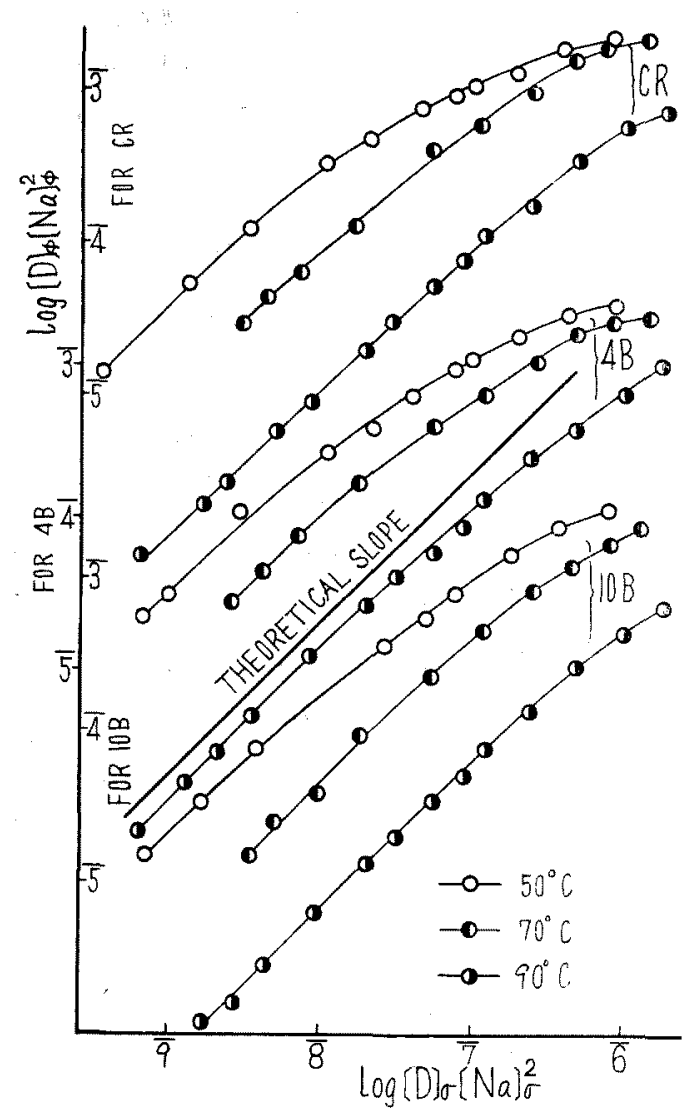

Fig. 3. Logarithmic plot of ionic products in the cellophane sheet and in the dyebath containing $2 \mathrm{~g} / \mathrm{l}$ $\mathrm{NaCl}$.
殺されていた，染料濃度增加にとすなら瀻維・染浴両: 相の活動度系数の減少 ${ }^{5)}$ が，濃厚部分で染浴側にかた よる。この活動度系数の減少は，招もに染料分子の解 離度の減少と，イオンの集合度增大に上るためと考点。 られる。

ii）吸着量の增加につれて, 飽和吸着量化対する比 率が大きくなり $\log \left([\mathrm{S}]_{a}-[\mathrm{D}]_{a}\right)$ をはぼ一定であるる みなすことができなくなる。

上記の活動度采数の減少に関する原因の5 占, 解離 度の減少については，ここで用いた䅘料がいずれも。 $z=2$ で文り，ままり問題とならない、6)とされているの で，i）で考虑しなければならないのは，主として集合 庭の增大である。桩散, 電気伝導度などの方法による 湘定から，水溶液中の直接染料集合しやすいことが わかつているので，染料濃度增加にともなら集合度の 变化を知るために染料水溶液の吸収スペクトルを測定: した。すでに谷崎らフは, 常温で CR, 4B, 10B の水溶 液腹を加之，染料分子の集合を增大させると可視 部の吸収極大が降下することをみいだしている。しが るに測定時の温度を $70^{\circ} \mathrm{C}$ にした場合の，各染料漶度 飞゙叔る極大吸收での分子吸光系数は第 4 图のように なり，染料灌情との間になんらの関倸もあらわれてい ない。一方，等温吸着線汇ついてみると，食塩無添加 の系列ではFig.1 のよ5な，吸着量が一定值に近つ く傾向は示さず，染料婊度とほぼ直線関係にあり，吸 着量ははるか以少なくなつている。すなわら，染料濃 度の增加に比して吸着量の增加がはなはだしく減少し てくるのは，吸着量が非常に多くなつた部分でのみみ

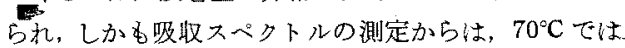

薄いところから溜い部分にわたり，できるだけ広 い籁用で（1）式の関係が成り立つ上5な值を選ん だ。これらの V を第 1 表に示す。いまの場合， 染着機構が（1）式老满足させるるのであるなら ば，第 3 図は全淟度範囲にわたり傾斜 $45^{\circ}$ の直線 (theoretical slope)と平行になるはずであるが, 結果はいずれる染着量の增加ととるに傾斜が小さ くなり理諭値との差が大きくなる。このような傾 向をるたらす版をな原因について考察すれば次の よ5な事項があげられる。

i）適刍なる V の値を用いることによつて相 第 1 表 Na办算出に用いた $\mathrm{V} \quad(l / \mathrm{kg})$

\begin{tabular}{c|c|c|c}
\hline Dye & $50^{\circ} \mathrm{C}$ & $70^{\circ} \mathrm{C}$ & $90^{\circ} \mathrm{C}$ \\
\hline $\mathrm{CR}$ & 1.00 & 0.93 & 0.60 \\
$4 \mathrm{~B}$ & 0.80 & 0.78 & 0.51 \\
$10 \mathrm{~B}$ & 0.71 & 0.70 & 0.50 \\
\hline
\end{tabular}

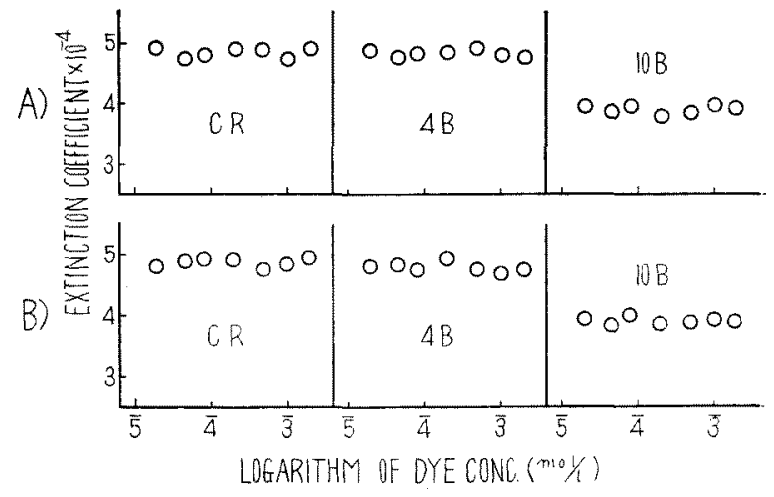

Fig. 4. The maximum extinction coefficient of the adsorption spectra of solutions containing various amounts of dyes: at $70 \mathrm{C}$.
A) Solutions containing $2 \mathrm{~g} / / \mathrm{NaCl}$
B) Solutions without $\mathrm{NaCl}$ 
食塩添加, 無添加の雨溶液とも, 染料淟度変化にともな5 集合度の変化は観察されない。以上のことから，濃厚部 分での吸着量の增加率の減少の主因としては，前記 i) の“染料濃度の増加にとるなら集合度增大”ょりも“染 着量が潟和染着量に対して然視できない大きさになつて いる”ためと考えるのがより妥当である。

それゆえ，(1) 式に飽和吸着量を考慮した項を入れる $z$
第 2 表 外揹上り求めた飽和吸着量 $[\mathrm{S}]_{a} \times 10^{9} \quad(\mathrm{~mol} / \mathrm{kg})$

\begin{tabular}{c|r|r|r}
\hline Dye & $50^{\circ} \mathrm{C}$ & $70^{\circ} \mathrm{C}$ & $90^{\circ} \mathrm{C}$ \\
\hline $\mathrm{CR}$ & 80 & 98 & 112 \\
$4 \mathrm{~B}$ & 93 & 95 & 107 \\
$10 \mathrm{~B}$ & 101 & 118 & 120 \\
\hline
\end{tabular}

第3 表 $2 \mathrm{~g} / l \mathrm{NaCl}$ 染浴の等温染着: $\mathrm{C}_{1}, \mathrm{C}_{2}$ の比較

\begin{tabular}{|c|c|c|c|c|c|c|c|c|c|c|c|c|}
\hline & \multicolumn{4}{|c|}{ CR } & \multicolumn{4}{|c|}{$4 \mathrm{~B}$} & \multicolumn{4}{|c|}{$10 \mathrm{~B}$} \\
\hline & $\begin{array}{c}\text { 染浴瀇度 } \\
(\mathrm{mol} / \mathrm{l})\end{array}$ & $\begin{array}{c}\text { 吸着量 } \\
(\mathrm{mol} / \mathrm{kg})\end{array}$ & $\mathrm{C}_{1}$ & $\mathrm{C}_{2}$ & $\begin{array}{c}\text { 染浴濃度 } \\
(\mathrm{mol} / \mathrm{l})\end{array}$ & $\begin{array}{l}\text { 吸㥬䁷 } \\
(\mathrm{mol} / \mathrm{kg})\end{array}$ & $\mathrm{C}_{1}$ & $\mathrm{C}_{2}$ & $\begin{array}{c}\text { 染浴濃度 } \\
(\mathrm{mol} / \mathrm{l})\end{array}$ & $\begin{array}{c}\text { 吸著量 } \\
(\mathrm{mol} / \mathrm{kg})\end{array}$ & $\mathrm{C}_{1}$ & $\mathrm{C}_{2}$ \\
\hline \multirow{14}{*}{$90^{\circ} \mathrm{C}$} & $\begin{array}{r}\times 10^{-5} \\
0.0543\end{array}$ & $\begin{array}{l}\times 10^{-3} \\
1.71\end{array}$ & 3.06 & 4. 02 & $\begin{array}{r}\times 10^{-5} \\
0.0503\end{array}$ & $\begin{array}{c}\times 10^{-9} \\
2.02\end{array}$ & 3.13 & 4. 11 & $\begin{array}{r}\times 10^{-5} \\
0.0660\end{array}$ & $\begin{array}{l}\times 10^{-8} \\
1.43\end{array}$ & 2. 80 & 3.73 \\
\hline & 0.140 & 3. 24 & 3. 05 & 4. 02 & 0.107 & 3.60 & 3.13 & 4. 13 & 0.138 & 2.81 & 2.85 & 3.78 \\
\hline & 0.200 & 4.16 & 3.05 & 4. 01 & 0.171 & 4. 99 & 3. 12 & 4. 12 & 0.225 & 3.21 & 2.72 & 3.65 \\
\hline & 0.422 & 6.89 & 3. 05 & 4. 03 & 0.289 & 6. 96 & 3.14 & 4. 14 & 0.365 & 5.13 & 2.80 & 3. 74 \\
\hline & 0.725 & 8.95 & 3. 01 & 3.99 & 0.697 & 11.3 & 3.15 & 4. 17 & 0.773 & 8.10 & 2.81 & 3.76 \\
\hline & 1. 62 & 13.5 & 3.00 & 4. 01 & 1. 63 & 16.0 & 3. 11 & 4. 15 & 1.69 & 11.8 & 2. 79 & 3. 76 \\
\hline & 2. 57 & 16.4 & 2. 97 & 3.98 & 2.64 & 19. 2 & 3. 11 & 4. 16 & 2. 61 & 14.4 & 2. 79 & 3.77 \\
\hline & 4. 50 & 20.9 & 2. 99 & 4.03 & 4.51 & 22.3 & 3. 03 & 4. 10 & 4.57 & 18. 1 & 2.78 & 3. 78 \\
\hline & 7.06 & 24.4 & 2. 96 & 4.01 & 7.03 & 26.1 & 3. 01 & 4. 10 & 7. 42 & 21.0 & 2.73 & 3.74 \\
\hline & 9. 35 & 27.9 & 3.00 & 4.07 & 9.42 & 29.6 & 3. 07 & 4. 18 & 9.83 & 24.5 & 2.78 & 3.80 \\
\hline & 19.4 & 33.8 & 2. 89 & 3.99 & 19.2 & 38.0 & 3. 02 & 4. 18 & 19.5 & 30.5 & 2.74 & 3.79 \\
\hline & 38.9 & 43.8 & 2. 89 & 4.06 & 38.8 & 44.6 & 2. 91 & 4. 12 & 38.4 & 39.0 & 2.65 & 3.74 \\
\hline & 79.2 & 52.0 & 2. 79 & 4.02 & 80.0 & 54.2 & 2.84 & 4.11 & 79.6 & 46.3 & 2. 64 & 3. 77 \\
\hline & 142. & 56.6 & 2.64 & 3.90 & 143. & 62.3 & 2.76 & 4. 12 & 144. & 58.0 & 2. 56 & 3. 77 \\
\hline \multirow{10}{*}{$70^{\circ} \mathrm{C}$} & 0.255 & 12.9 & 3. 98 & 5.05 & 0.223 & 14.4 & 4.02 & 5.13 & 0.292 & 10.8 & 3.63 & 4. 60 \\
\hline & 0.375 & 16.1 & 3.99 & 5.07 & 0.346 & 18.3 & 4.04 & 5.15 & 0.410 & 14.6 & 3.70 & 4.68 \\
\hline & 0.603 & 19. 5 & 3.94 & 5. 05 & 0.589 & 23.3 & 4.05 & 5. 19 & 0.806 & 17.4 & 3. 60 & 4.60 \\
\hline & 1. 45 & 27.0 & 3.87 & 5.02 & 1. 50 & 32.2 & 3.99 & 5.19 & 1.51 & 25.5 & 3.71 & 4.75 \\
\hline & 4. 36 & 43.3 & 3.89 & 5.15 & 4. 51 & 44.6 & 3. 88 & 5.17 & 4. 40 & 36.0 & 3.63 & 4.69 \\
\hline & 9.38 & 51.1 & 3.74 & 5.07 & 9.73 & 53.2 & 3. 75 & 5. 13 & 9.51 & 46.3 & 3. 59 & 4. 73 \\
\hline & 20.0 & 60.1 & 3.61 & 5.03 & 20.8 & 66.8 & 3. 69 & 5.23 & 20.0 & 57.3 & 3. 52 & 4. 71 \\
\hline & 37.3 & 72.1 & 3.55 & 5.13 & 38.4 & 73.3 & 3.54 & 5.20 & 35.9 & 64.9 & 3. 41 & 4. 69 \\
\hline & 60.8 & 76.9 & 3. 43 & 5.11 & 65.0 & 78.5 & 3. 39 & 5.16 & 62.5 & 73.5 & 3.32 & 4. 67 \\
\hline & 102. & 80.3 & 3.21 & 5.04 & 105. & 80.8 & 3.20 & 5. 12 & 101. & 80.5 & 3.24 & 4.67 \\
\hline \multirow{11}{*}{$50^{\circ} \mathrm{C}$} & 0.0218 & 6.30 & 4.62 & 5.72 & 0.0582 & 11.9 & 4.49 & 5.58 & 0.0581 & 10.0 & 4. 30 & 5.30 \\
\hline & 0.109 & 17.2 & 4.62 & 5.77 & 0.0854 & 14.6 & 4. 48 & 5.58 & 0.139 & 16.0 & 4. 30 & 5.37 \\
\hline & 0.279 & 25.6 & 4.55 & 5.77 & 0.258 & 26.0 & 4.54 & 5.71 & 0.318 & 23.0 & 4. 29 & 5.39 \\
\hline & 0.863 & 38.5 & 4. 48 & 5.80 & 0.944 & 37.5 & 4. 37 & 5.63 & 1.07 & 31.7 & 4. 11 & 5.33 \\
\hline & 1. 70 & 45.6 & 4.37 & 5.78 & 1.88 & 43.1 & 4. 23 & 5.52 & 2. 10 & 42.4 & 4. 14 & 5.36 \\
\hline & 3.62 & 54.3 & 4.24 & 5.71 & 3. 41 & 52.0 & 4. 20 & 5.58 & 4. 05 & 49.0 & 4.03 & 5.32 \\
\hline & 5.91 & 59.2 & 4.13 & 5.70 & 6.22 & 60.0 & 4.10 & 5.58 & 6.24 & 56.2 & 4.01 & 5. 36 \\
\hline & 8.30 & 62.4 & 4.04 & 5.66 & 7.99 & 63.4 & 4. 06 & 5.58 & 7.78 & 60.0 & 4.00 & 5.39 \\
\hline & 15.0 & 67.0 & 3,88 & 5.65 & 16.5 & 72.1 & 3.90 & 5.58 & 13.9 & 69.1 & 3. 92 & 5.38 \\
\hline & 30.1 & 75.8 & 3.72 & 5.72 & 33.2 & 79.3 & 3.71 & 5.58 & 28.3 & 77.0 & 3.74 & 5.36 \\
\hline & 66.1 & 81.4 & 3.45 & 5.79 & 65.6 & 85.4 & 3.51 & 5.58 & 60.4 & 85.6 & 3.55 & 5.36 \\
\hline
\end{tabular}




$$
\begin{aligned}
\log [\mathrm{D}]_{\phi}[\mathrm{Na}]_{\phi^{z}}-\log [\mathrm{D}]_{\sigma}[\mathrm{Na}]_{\sigma^{z}} \\
=\mathrm{C}_{2}+\log \left([\mathrm{S}]_{a}-[\mathrm{D}]_{a}\right)
\end{aligned}
$$

$[\mathrm{D}]_{a},[\mathrm{~S}]_{a}$ は繊維素吸着界面の吸着量およびその飽和量 で屴る。 $[\mathrm{S}]_{a}$ は表面溶液譄の㳻度の逆数に対して $1 /[\mathrm{D}]_{a}$ をブロットした外挿值より求めた。ただし表面溶液圈の 濃度は，Donnanの膜平衡より $[\mathrm{Na}]_{t}^{z}[\mathrm{D}]_{t} /[\mathrm{Na}]_{\sigma}^{z}[\mathrm{D}]_{\sigma}$ $=1$ （添字 $i$ は表面溶液賚濃度を指す）したがつて $[\mathrm{D}]_{i}=\left([\mathrm{Na}]_{\sigma} /[\mathrm{Na}]_{\ell}\right)^{z}[\mathrm{D}]_{\sigma}=\left([\mathrm{Na}]_{\sigma} \mathrm{V} /[\mathrm{Na}]_{\phi}\right)^{z}[\mathrm{D}]_{\sigma}$

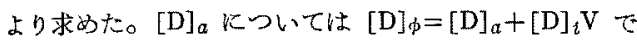

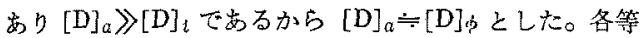
温吸着線からの結果を第 2 表儿示す。

いま食塩添加の染色結果沉ついて，ここに得られた $[\mathrm{S}]_{a}$ を(3) 式に適応したときの $\mathrm{C}_{2}$ と，(1) 式からの $\mathrm{C}_{1}$ について比較すると第 3 表のよ 5 になり， $\mathrm{C}_{1}$ より。 $\mathrm{C}_{2}$ の方がより一定な值となつている。したがつて標準 親和力をこれより求めるには，当然の結果として $\mathrm{C}_{2}$ を 用いた方がり一定な值を得ることができ，木た值も大 きくなる。

\section{5. ま め}

CR，4B，10Bの七ロハン染色について等温吸着曲線 を求め，これに対する Vickerstaff の等温吸着式の適応
性を検討した。その結果，染着量が $4 \sim 5 \times 10^{-2} \mathrm{~mol} / \mathrm{kg}$ 以上の濃厚染色ては, 親和力の算出にあたり飽和吸着量 との閣連性を考慮すると，無視した場合に比して大きな 值をとることになる。すなわち，ここでは飽和吸着量に 対する吸着量の比率が大きくなり, $\log \left([\mathrm{S}]_{a}-[\mathrm{D}]_{a}\right)$ の 項を親和力のなかに含ませてしまうのは不適当であるこ とが明らかとなつた。

本研究は，昭和 35 年度文部省内地研究員として東京 工業大学で行なつた。ご指導をいただいた安藤教授なら

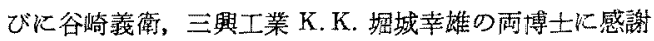
する。(昭和 36 年 4 月 日本化学会第 14 年会で講演)

$$
\text { 文 }
$$

献

1) J. Hanson, S.M. Neale ; Trans. Far. Soc., 30 , 386 (1934)

2) T. Vickerstaff; The Physical Chemistry of Dyeing 2 nd Ed., 201 (1954)

3) R.H.Peters, T. Vickerstaff ; Proc. Roy. Soc., (London), A 192,292 (1948)

4) Y. Horiki ; Bull. Chem. Soc. Japan, 33, 974: (1960)

5) M. Nakagaki ; ibid., 29, 201 (1956)

6) 浦畑俊博；䋐学誌，15，314(1959)

7) 谷崎義衛, 安藤僬; 吕化, 78,343 (1957), 